\title{
A Gente é Cria de Frases: sobre história e biografia
}

\author{
Durval Muniz de Albuquerque Júnior \\ Universidade Federal do Rio Grande do Norte
}

A morte colhe a Érico Veríssimo em plena escrita de sua autobiografia. O seu Solo de Clarineta queda-se interrompido, silenciado por este encontro inevitável para todos os humanos. ${ }^{1}$ Em conversa com Flávio Aguiar já demonstrara o temor de que lhe faltasse tempo para concluir suas memórias. ${ }^{2}$ Memórias que, durante muito tempo, jurou que não iria escrever, por temer resvalar para uma ridícula autovalorização. ${ }^{3}$ Mas, incomodado com as várias versões que circulavam sobre sua vida, resolve contar a sua própria história, como uma errata das várias versões de si mesmo. ${ }^{4}$ Nesta resolução, o medo de que após sua morte viessem a prevalecer estas biografias não autorizadas. Nesta resolução, o medo e a presença da morte, desta morte ferramenta, como nos diz Blanchot, esta que é sempre vizinhança e ausência, mas que permite e autoriza a obra, que permite o texto biográfico e autobiográfico. ${ }^{5}$ É preciso ainda não estar morto para poder escrevê-los, mas é preciso sentir-se já morto, com a vida concluída, fechada, para poder iniciar a escrita, para poder tomar a decisão de escrever. Discurso de despedida, como o próprio Érico chega a admitir, embora para denegar esta idéia rapidamente, como sendo mórbida ${ }^{6}$, a autobiografia encena este jogo perigoso com a morte, e através dele busca ligar uma vida a história, busca dar uma forma memorável a um nome que recobriu, durante um espaço de tempo, a existência de um corpo, um conjunto disperso e incontável de ações, de práticas, de acontecimentos, de pensamentos, de vivências, de relações, de feitos e defeitos.

Biografar, escrever uma vida, dizer o que ela foi, desvendar-lhe o segredo, dizer sua verdade, é possível? Memorizar uma vida individual, dar-lhe uma história, é recuperar o que foi o seu Eu? Érico Veríssimo ao longo de sua autobiografia parece oscilar entre respostas distintas para estas perguntas. Afirma 
que não se escreve biografia sem contar uma história, história que seria retificadora de outras versões, a verdade de si. $^{7}$ Mas, história que sabe fragmentária, como uma colcha de mágicos retalhos arrancados ao tecido do tempo ${ }^{8}$, da qual se consegue recuperar alguns fragmentos mais significativos, aqueles que emergem da nebulosa que é a memória, aqueles que por vezes vem à tona, relampejam num dado momento aos acasos dos encontros, em que figuras, paisagens, sensações e sentimentos passados são evocados e se embaralham com acontecimentos presentes, onde lembranças se confundem produzindo uma espécie de aquarela apagada pelo tempo. ${ }^{9}$ Nesta história apresenta-se como um ser binário: estóico, imperturbável, sério, responsável, trabalhador, contido, até moralista em sua aparência exterior, carapaça, superego que protege e sitia um interior que seria vulnerável, tímido, sensível, com tendência ao tédio e à preguiça, onde habitaria um pícaro, um satírico, um cético, que espiaria com desconfiança, indulgência e, às vezes, com rigor este Eu que aparece em público. ${ }^{10}$ Mas, à medida que escreve sua autobiografia, descobre ter vários eus, incontáveis, e alguns até inconfessáveis. Multiplicidade que é agravada pelo fato de ter sido, durante grande parte do tempo, um ficcionista, um romancista, um criador de personagens, um homem que precisava viver outras vidas, sentir, pensar e agir através de outros sujeitos. Em muitos deles, tendo podido realizar, quem sabe, muitos outros eus que o habitavam mas que em si próprio foram proibidos de atuar.. ${ }^{11}$ Mas, apesar de ser múltiplo, apesar de ter constatado quão fragmentária e errante fora sua vida, não deixa de encontrar, num gesto de apaziguamento final, um sentido para toda a sua vida e para toda sua obra, um sentido que, alcançado na vida cotidiana, foi fruto do trabalho quase terapêutico do ato de escrever, foi resultado material e espiritual da obra realizada: elas ganham sentido através da busca do lar e do pai perdidos. Reconstruído seu lar e reconciliado com seu pai, tendo-se tornado pai de si mesmo, Érico vivencia aquela sensação de plenitude, de satisfação consigo mesmo, que o avizinha da própria morte, e que, talvez, por isso o faça lembrar de si mesmo, o faça apressar-se em dizer-se. ${ }^{12}$

A escrita autobiográfica, este último gesto do autor de ficção, talvez seja, justamente, não apenas uma maneira de fazer-se lembrado, mas de lembrar de si mesmo, de sua existência cotidiana, daquele que foi ou que é quando não escreve, aquele que resta ou existe antes ou apesar dos personagens que criou ou cria. Último gesto na busca de não renunciar a si mesmo, de se enraizar 
no tempo e na história, a autobiografia representa uma espécie de confissão de quem já não tem muita certeza de pertencer ao tempo, ao seu tempo. ${ }^{13}$ Ela nasceria do temor de não mais se pertencer à história, de vê-la escapar por entre seus dedos, de quem por isso não pode perder tempo, na busca de um sentido de conjunto para sua existência, na busca de fazer sentido. $\mathrm{O}$ medo de desaparecer sem deixar um nome ou deixando um nome equívoco leva à escrita biográfica, leva a que se aposte na escrita, no texto como forma de estabilizar uma figura, uma identidade, como forma de perenizar, de monumentalizar uma vida, um corpo que já dá sinais de cansaço, que no espelho já parece outro, já o interpela como um estranho, já faz para ele perguntas incômodas. A escrita, as palavras que vão registrar sua vida parecem ser as últimas armas que tem para seguir vivendo, escrever como uma forma de ludibriar a morte, de prolongar a existência. Enquanto estiver escrevendo, enquanto ainda tiver algo a contar, a dizer, enquanto ainda não tiver colocado o ponto final em sua obra, a morte será protelada, o encontro fatal não irá se realizar. ${ }^{14}$

Mas a escrita, esta companheira de toda uma vida, a rival permanente de Mafalda, será mesmo capaz de imortalizá-lo? Logo ele que nunca acreditou na imortalidade. Será a escrita capaz de dizer afinal aquilo que passou a vida procurando e parece ter afinal encontrado: o seu Eu? Ao se entregar à escrita autobiográfica, o cético Érico parece finalmente ter sido vencido pelo Veríssimo, indo em busca de sua verdade, mesmo que não necessariamente superlativa. Não terá sido excesso de confiança em sua companheira de trajetória? Biografar é escrever sobre uma vida, autobiografar é escrever sobre si mesmo. Mas afinal o escrever autoriza estes gestos? O que significa escrever? Para Maurice Blanchot escrever é, justamente, 'quebrar o vínculo que une a palavra ao eu, quebrar a relação que, fazendo-me falar para ti, dá-me a palavra no entendimento que essa palavra recebe de ti, porquanto ela te interpela, é a interpelação que começa em mim porque termina em ti'. ${ }^{15}$

Como é possível, portanto, dizer-se Eu escrevendo se, a cada vez que se escreve, a palavra surge estranha, apartada deste Eu, entregue a um outro que lhe vai ler e dar sentido? Ao tentar estabilizar um sentido para o Eu através da escrita, o biógrafo o joga no vórtice da leitura, da dotação de sentido, no interminável e incessante que é o escrever. ${ }^{16}$ Para dizer o ser, o entrega às forças obscuras da escrita. Tenta voltar ao informe caldo original, ao mingau do tempo e daí fazer brotar uma forma, uma figura, esculpida com palavras. ${ }^{17}$ 
Mas como recordar a si mesmo usando o próprio elemento do esquecimento, o escrever? ${ }^{18}$

Ser escritor é justamente perder o poder de dizer Eu a não ser para si mesmo. Como diz Kafka, em seu Diário, só se começa a escrever quando se aprende a passar do Eu para o Ele, quando se aprende a se entregar a um Outro, a ser outros. ${ }^{19}$ O próprio Érico reconhece que só se faz literatura abrindo mão do elemento autobiográfico, o transmutando, o modificando, embora este não deixe de restar presente como fantasmas, como aqueles esboços, aqueles desenhos que costumava fazer de seus personagens, antes de transformá-los em escrita. A literatura, que foi sua vida, o arrastou para fora de si e, agora, através das memórias tentava salvar suas relações com o mundo e consigo mesmo. ${ }^{20}$ Mas como fazer isto escrevendo, se escrever é fazer eco a uma fala que circula socialmente, coletivamente, é participar de um enorme arquivo de textos, de outros escritos, de outros enunciados lidos e escutados, que ameaçam todo tempo o autor com o perigo do plágio? Talvez seja, justamente, aquilo que o autor silencia, aquilo que não diz, como a cena de violência que pôs fim ao casamento de seus pais, que permanece inteiramente seu. Somente este gesto de impor silêncio, este gesto de pudor e, talvez, de vergonha, é parte de si mesmo, é talvez o único que possa dizer Eu. ${ }^{21} \mathrm{~A}$ autoria, o indivíduo que escreve, o Eu do escritor, com seu estilo, se revelariam na autoridade de silenciar, de não dizer, de não contar, naquilo que não é dito e escrito. O silêncio é o que resta de si neste texto que o apaga no mesmo gesto que o escreve, que o põe à margem no mesmo movimento que o traga para dentro do escrito. Como diz Michel de Certeau, na escritura, o ser bordeja o texto, o corpo se instala em sua margem, o Eu se reserva para aparecer outro, mesmo quando fala de si mesmo. ${ }^{22}$

Neste escrito que busca ser confessional, que busca falar de si, Érico se preocupa em se mostrar como um ser social, um ser histórico, um ser político, um ser universal. Logo na abertura do volume 2 de suas memórias, reproduz um discurso feito por ele, em 1956, na Pontifícia Universidade Católica de Porto Alegre, num ato público em protesto pela invasão da Hungria por tropas soviéticas, em que apareceriam de forma clara sua posição política, suas idéias sobre o mundo e sobre os homens, sua visão sobre a história. Julgando-se incompreendido, Érico busca se explicar, e ao fazê-lo se dissolve em meio a outros tantos que partilharam das mesmas idéias 
e opiniões, que tiveram as mesmas atitudes, que sentiram e pensaram coisas parecidas. ${ }^{23}$ Como um escritor clássico, falando de si, abandona a fala que é própria, para dar voz ao universal. ${ }^{24}$ Neste passo o Ele toma lugar do Eu, o anonimato vem habitar seu escrito biográfico. O Eu se torna muitos e ninguém em especial. Ao dirigir-se a outrem para se fazer entender, já não é ele mesmo. Para se comunicar, precisa estabelecer relações de significação, precisar abrir este Eu em direção ao outro e, nesta abertura, este retorna sempre modificado, sempre atravessado pela presença alheia, por rostos, corpos e paisagens estranhas, estrangeiras. Como interiorizar, como produzir um Eu com estes fluxos exteriores, este fora que é a linguagem e o mundo? ${ }^{25}$ Escrever é se comunicar em busca de se produzir, buscar encontrar-se no exílio de si mesmo. ${ }^{26}$ Nesta abertura o biográfico toca o histórico, pois o Eu abre-se para o mundo.

Escrita para a morte, a biografia é a busca de fazer renascer alguém, no mesmo gesto que enterra o mundo em que viveu. Mundo no qual busca entrar, do qual busca fazer parte, apesar de tudo. Decreta-se o passado daquele mundo para lá alojar um ser, que olha para trás como um estrangeiro. Um ser que do mundo da linguagem busca compreender este mundo que ainda o repele. O biografado é um ser abandonado no limiar entre a vida e a morte e que, nesta fronteira, neste espaço, tenta encontrar-se, conhecer-se, sem suportar este encontro e este conhecimento que o revela natimorto. Abandonado na terra natal, no nascimento, nasce quando se abandona à escrita; encontra-se quando se separa de si mesmo, escrevendo. O texto autobiográfico é uma busca de si mesmo que só cessa com a morte, pois é uma busca por um ser que sempre se afasta, que sempre se retira numa migração infinita, horizonte sempre inalcançável, terra prometida sempre descoberta como deserto. Mas ele também é uma conquista, a conquista da própria perda, a conquista de uma liberdade de perambular, de vagar por inúmeros eus. Ele contém uma verdade, a verdade do exílio e do retorno ao próprio seio da dispersão. ${ }^{27}$ Érico fala, inúmeras vezes, desta sensação de ser exilado, de ser solitário, de ser estranho, de ser estrangeiro no mundo. Seu Eu nunca parece corresponder ou estar confortável em nenhum lugar. Em Cruz Alta, Porto Alegre ou em Nova York, sempre parece estar fora do lugar, vestido com a roupa imprópria, parece ser um gato preto em campo de neve $e^{28} \cdot{ }^{29}$ Parece haver uma hesitação em relação à própria existência, ao nascimento. Com o texto autobiográfico 
o que busca é afirmar-se, é convencer-se de que nasceu de verdade nem que seja através dos livros, que foi filho, nem que seja de si mesmo.

Érico Veríssimo, como Kafka, talvez se tenha feito escritor, para encontrar um lugar para si, para, como ele mesmo diz, encontrar um lar, já que, como o autor tcheco, desde cedo, por culpa do pai ausente, se sentiu jogado no mundo, condenado à solidão, condição precípua para que haja escrita, para que se balbucie Eu. ${ }^{30}$ Este ser perdido, errante no mundo, quer encontrar uma verdade para si no texto, na escrita, na paralisia da folha de papel que enche com palavras, mas aí a errância se reinicia. Não sabe ao certo nunca se poderá novamente escrever, se sabe escrever, se será lido, se será entendido, como será interpretado. Mas o escrever lhe aparece como esta abertura para outros mundos, maiores e menos sufocantes, menos opressores do que aqueles em que vivia. A autobiografia é esta última abertura, é esta última lufada de ar para quem pressente o sufoco da morte, para quem já quase havia morrido sufocado ${ }^{31}$. A autobiografia é esta oportunidade de se tornar este Ele que observa o seu Eu, que o olha de fora, que dele se distancia, elevando-se acima de sua realidade mortal, de seu ser mortal. Este Eu que fala e vê na autobiografia já é imortal, já habita outro mundo, já experimenta a suprema liberdade, a de não morrer, a de não ser mortal. ${ }^{33}$ Este Eu por escrito pode zombar ou até se comover com este outro que não tem existência por escrito, que tem sentidos mas não vive apenas no sentido. Tornar-se o pai de si mesmo é, talvez, exercer esta soberania sobre a sua própria vida, ter o controle sobre si, ter esta autoridade, este domínio sobre o seu próprio destino, sobre a escrita de si, que este olhar de fora o permite. O texto autobiográfico nasce desta consciência da finitude e da infelicidade daquele que um dia não mais poderá dizer Eu. Autobiografia, texto de consolação, um sopro de alegria tomado emprestado do nada, da ilusão do escrever como um ato de afirmação, de definição, de purificação do Eu, um gesto que elevaria o ser ao verdadeiro, ao inalterável e ao incorruptível. ${ }^{34}$

Por meio da escrita biográfica, este ser situado no tempo, passageiro da vida, quer ser atemporal, no mesmo gesto que narrando constrói a própria temporalidade. Invenção do ser de si e do próprio tempo como unidades indissolúveis. Esta busca da unidade do Eu, de sua coerência ao longo do tempo, de sua recorrência, é a marca da escrita biográfica. Ela quer ser a representação do sujeito que fala, mas para isso tem que dele se separar, tornar-se 
imagem, película que se interpõe entre o ser e o re-apresentar, representação que ganha irradiação própria, que fascina, e que termina por dispersar aquele que quis apresentar como unitário. A imagem, como tal, jamais pode ser alcançada, espelho que se afasta inatingível, heterotopia do Eu, espelho que se quebra aos pedaços ao ser tocado. Érico tinha o hábito de conversar com o outro que via nos espelhos na hora de se barbear, outro que devolvia a Ele uma imagem sempre distinta daquela que fazia de si mesmo, que o levava a incerteza de si mesmo. Esta incerteza só faz se agudizar quando através da narrativa busca dizer quem é, pois cada vez que narra todo o seu ser volta a ser posto em questão. Nestas horas, é tomado por uma espécie de febre, de arrebatamento, de paixão, que se materializam em doenças psicossomáticas, em doenças gástricas. A obra que vai nascer o tensiona como um parto. Para vir à luz, a obra o desgasta mais um pouco, o aproxima ainda mais da morte. A obra que vai garantir sua existência, que vai lhe dar sobrevivência, que vai lhe dar presença no mundo, é a mesma que vai irremediavelmente o aproximando da passagem final. A autobiografia encena, de maneira particular, o conflito entre escrever e pertencer ao mundo, pertencer à história, pois escrever implica ter mais tempo e menos mundo, mais solidão e menos mundanismo. ${ }^{35}$ Érico, em vários momentos de suas memórias, se queixa do tempo que seus compromissos pessoais e sociais the retiravam da escrita.

Ainda, agora, na urgência do texto autobiográfico, neste texto assombrado pela ausência de tempo, as convocações do mundo o vêm atrapalhar. É preciso para ficar no mundo, retirar-se dele, pelo menos nestes últimos momentos. Érico quer conhecer a si mesmo, quer conhecer sua obra, quer dar a chave dos segredos de si e do que escreveu, quer dar de si um retrato, por isso planeja uma autobiografia. Mas, como de costume, planeja uma obra que exige muito tempo, tempo de que já não dispõe. Agora, o escritor de sagas vê a sua chegar ao fim, mas ainda quer se dizer e dizer sua obra em três volumes. Será que não aprendera que escrever é interminável, é incessante, que a obra só se encerra sob a ausência do autor, que o Eu nem com a morte se estabiliza? A traiçoeira, a inesperada, o acontecimento intransponível vem antes de concluir o segundo volume de suas memórias, que quedam inacabadas. Mas poderia ser diferente? Mesmo que tivesse sido ele a colocar o ponto final em sua autobiografia, esta seria mesmo um texto fechado, concluído? Como morreu, deixando apenas fragmentos do que seria o final do segundo e partes 
do terceiro volumes, logo a família reabre a sua biografia, reabre a sua vida, convoca a um terceiro, a um Outro para organizar o segundo volume do seu Solo de Clarineta. ${ }^{36}$ Mas já não era um Outro que escrevia sobre ele, mesmo estando ainda vivo? Este Outro que é o autor, que é o sujeito da escrita, que é o escritor, o historiador de uma vida? Mas estivemos falando até agora de um historiador de vidas muito particular, que fala do que teria sido a sua própria vida, embora não tenha deixado de falar de várias outras que não a dele, que inventou outras tantas, porque ele foi durante todo tempo um escritor, um autor de ficção. Mas se fosse um outro tipo de historiador de vidas, se fosse um historiador profissional, que fala de personagens que devem realmente ter existido, as regras da escrita biográfica se modificariam? Quais as particularidades da escrita biográfica quando feita por um historiador? Mesmo sabendo que Érico se considerava um autor tão realista, que chega a imaginar, numa visita ao Rijksmuseum, em Amsterdã, que o espectro de Rembrandt lhe admoestava por ser fascinado pelo aspecto exterior dos objetos e das pessoas, confundindo romance com inventário, ficção com fotografia, o que faria de seu texto autobiográfico um texto diferente daquele escrito por um profissional da história ${ }^{37}$ Mesmo que Érico, o Veríssimo, tenha resolvido escrever romances sobre a história do Rio Grande do Sul, por considerar que a história que lera e estudara de seu Estado não passavam de ficções, por isso fizera ficção de ficção ${ }^{38}$, qual seriam as diferenças entre o texto biográfico escrito por um romancista e um escrito por um historiador?

A biografia histórica já é, de saída, a escrita de uma terceira pessoa, uma escrita que diz Ele, embora se empenhe em escrever um Eu. O historiador que ocupa um lugar de autoria pretensamente sem fisionomia, um coletivo impessoal, escreveria em outro nome, escreveria não em nome próprio, escreveria em nome da ciência histórica, escreveria em nome das regras que o autorizam a escrever, escreveria em nome de uma categoria, escreveria em nome da verdade, escreveria no lugar do conhecimento. Aquele que assume a face da instituição historiográfica, é apenas um Alguém, que escreveria de um lugar temporal, espacial, social, que obedeceria a uma disciplina, que fabricaria um texto onde seu rosto não viria se alojar, de onde seu Eu estaria retirado ${ }^{39}$, quando não acredita que é a própria história que se escreve através dele, simples cavalo a incorporar e psicografar o espírito da história. Se na literatura a linguagem enrosca-se sobre si mesma, ela não fala, ela é, sempre, 
começo e recomeço absoluto, na história a linguagem se abre para um fora, para um resto, para um real, para um testemunho, para um documento, algo que indicie a existência no tempo daquilo que vem habitar o texto. ${ }^{40} \mathrm{~A}$ história é uma escrita em busca de sair de si, que busca pontos de referência que a autorizem, fora de si mesma, embora, quase sempre, estes pontos de referência sejam outros textos. Textos memoriais, textos que apontam para a vida cotidiana, que indiciam marcas e marcos, que cheiram à vida, que carregam em si traços dos corpos e dos eventos aos quais vieram se misturar, dos quais foram uma peça, nos quais se envolveram, nos quais tiveram presença, e por isso agora surgem como o que evita a ausência daquele que se foi, daquele que é passado, daquele que morreu. Textos, coisas que pertenceram ao comércio do mundo, que foram agentes de sua dramaturgia, que foram objeto e produto de ação ordinária, que pertenceram a um presente ativo, textos e coisas que tiveram duração e por isso avançaram até o amanhã, onde agora interpelam o historiador e lhe pedem que novamente os faça ter sentido, os faça agir, atuar, desempenhar, ser algo ou alguém. A história se escreve como salvaguarda do evento, da pessoa, dos incidentes do mundo, para que sejam enraizados no tempo, para que sejam capazes de pertencer ao tempo, de pertencer ao tempo do historiador.

Enraizar no tempo, criar a temporalidade para algo e para alguém, esta é tarefa primeira do historiador. A biografia histórica trata de enraizar um Eu no tempo e, por isso mesmo, abri-lo para o comércio com o mundo, com as pessoas, com as coisas, com as instituições, com as relações que co-existiram com este ser que se biografa. Se a literatura é o fascínio da ausência de tempo, do tempo absoluto, do eterno presente, do que sempre se escreve agora, do que se passa agora, do que se lê agora, a história é a presença do tempo, um tempo onde tudo já começou, onde o passado vem se alojar em primeiro plano, onde o presente se afirma apenas como mediador entre o passado e o futuro, local de encontro do espaço da experiência com o horizonte de expectativa, onde tudo é apenas recomeço, retorno, releitura, reescrita. ${ }^{41} \mathrm{O}$ escritor é dono do tempo do que escreve, o simula como quiser, por isso talvez ele tema tanto o tempo de sua própria vida, o tempo da história, e talvez por isso protele tanto a escrita autobiográfica, onde os tempos de seus escritos vêm se entrelaçar com os tempos de seu estar no mundo, tempo incontrolável, tempo que o arrasta para a morte. O historiador, de saída, afronta estes 
tempos mortais, estes tempos que não têm dono; se expõe a esta abertura para o infinito e para a finitude, para estes tempos que só encontra naquilo que estes mesmos tempos arruinaram, fragmentaram, esqueceram, silenciaram, atiraram para os arquivos, para os museus, para as bibliotecas, transformaram em lendas, em mitos, em monumentos, em documentos, naquilo que os tempos mataram.

O historiador, ao contrário do escritor, lida com a linguagem ordinária, com a linguagem das pessoas e tempos a que se refere, tenta lidar com a fala imediata, o que provoca a sensação de estar se relacionando com o mundo imediato, embora, como nos diz Blanchot, esta fala comum não passe do longínquo velado, do que é somente o habitual, o reconhecido. ${ }^{42} \mathrm{O}$ historiador faz o absolutamente estranho passar por familiar, por habitual, torna o insólito rotineiro. O historiador usa a linguagem para dizer uma vida, para biografá-la, de modo a fazer esquecer que a linguagem está aí, que é ela que está presente e não a vida de quem fala. Enquanto o escritor deve lembrar do ser da linguagem, o historiador deve produzir seu esquecimento, daí toda a ira de vários historiadores contra aqueles que afirmam o ser da linguagem. $O$ historiador usa a linguagem para devolver ao mundo pessoas e coisas, devolvê-las ao mundo como abrigo, ao mundo como meta, como projeto, mas se recusa a colocar no mundo a própria linguagem. Para dizer o ser através da linguagem o historiador deve fazer calar o ser da linguagem. Se na poesia são os seres que se calam, se aí apenas a linguagem fala, na história apenas os seres falam: a linguagem se recolhe para uma ausência, para um não estou aqui. Poesia e história, jogos com a linguagem, jogos de linguagem, mas que possuem artimanhas, estratégias distintas. Para falar de uma essência que estaria fora da linguagem, o historiador denega a linguagem como essência, pois esta deve designar alguém, um Eu que está fora da própria linguagem. Ela serve para dar voz a Alguém, um Outro daquele que fala. Se a literatura é objeto de linguagem, a história embora também o seja, se refere a um objeto que é separado, distante, anterior, externo à linguagem. A biografia histórica é uma construção de palavras que tem que recusar o ser das palavras para remetê-las a um ser que existe ou existiu apesar delas, que as espreita de fora, que lhes daria sentido. O discurso historiográfico só ganha sentido, só ganha legitimidade, se não gira em torno de si mesmo, como o 
discurso literário, mas se gira em torno de algo que lhe é externo, algo que aconteceu, a um evento, a um corpo, a um sujeito que o interpela de fora.

Se a literatura é a afirmação do poder das palavras de fazer as coisas e as pessoas aparecerem e desaparecerem, a história lida com coisas e pessoas que já apareceram e desapareceram no mundo ordinário, cotidiano, mas que, por isso mesmo, só podem reaparecer através das palavras. Mas os historiadores têm que fazer este reaparecimento sem chamar atenção para as palavras que o permite, mas usá-las para apontar, indiciar, estas coisas e pessoas desaparecidas, como se estivessem novamente aí, entre nós. Se a gente é cria de frases, o historiador usa as frases para pretensamente falar das gentes e das coisas. ${ }^{43}$ Colocá-las pretensamente ao abrigo da morte, fazê-las novamente presenças atuantes. Mas será mesmo? O trabalho na história, o trabalho de história, a ação no mundo, a prática de escrever o mundo, o esforço comum pela verdade, não impedem o desaparecimento de coisas, de sujeitos, de eventos; estes sonhos de sobrevivência se desvanecem quando pensamos que escrever já é também destruir, desconstruir, desfazer sentidos, tramas, figuras, imagens, conceitos, versões. Isto é que torna o ato de escrever, inclusive a história, um ato de liberdade. A lembrança, a memória, a história não são o aprisionamento do passado, mas sua libertação. O passado alça vôos para novos sentidos, para novos significados, para novas leituras, para nova organização. Pessoas e coisas passadas, quando tomadas pelo discurso da história, se libertam de sua materialidade rasteira, ordinária, banal, fatual, para ganhar novos corpos e novas figuras feitos de significações, morrem para se libertarem. Escrever uma biografia histórica não é devolver um Eu à sua materialidade cotidiana e ordinária, não é chegar a sua realidade, a sua essência, que descobriríamos talvez ser apenas a morte, o ser para a morte que todos somos, o nada que somos. Se os significados sociais, culturais e históricos não viessem a se agrupar em torno de nosso corpo, em torno do nome que o recobriu desde o nascimento, falar deste Eu seria impossível. É deste ser, composto de camadas de relações sociais, de significações culturais, de sentidos históricos, que o historiador escreve a biografia. O historiador faz uma arqueologia que se detém em escavar algumas das muitas, das inabarcáveis camadas, das inúmeras peles de vivências, de memórias, de experiências que ficaram registradas e relatadas em algum tipo de linguagem, sobre um dado ser. Relatos que testemunham sua existência, no mesmo gesto que a definem, a classificam, a 
dizem, a fazem ser vista. A biografia histórica não é, pois, o reencontro com a unidade de um ser, mas com a dispersão de um aparecer, do aparecimento de um mesmo nome em relatos e testemunhos que atribuem a este nome uma ação, uma prática, um pensamento, um sentimento, um gesto, uma emoção, uma obra, uma vida. O historiador apenas dará a este Eu uma nova organização ou o fará retornar a esta dispersão que o constitui, a este rosto arlequinal, caleidoscópico com que nos olha e nos convoca a decifrá-lo, como uma Esfinge em pedaços que não cessa de nos enviar novos enigmas, de nos enviar novas imagens, de nos fazer chegar novos sons. Alguns, verdadeiras orquestras, outros, somente bandas de jazz, alguns, como pretendeu Érico Veríssimo, ao escrever suas memórias, apenas um solo de clarineta. ${ }^{44}$ 


\section{Notas e Referências}

1 Érico VERÍSSIMO. Solo de Clarineta: memórias, 2 vols. $20^{\mathrm{a}}$ ed. São Paulo: Companhia das Letras, 2005.

2 Idem, p. 289.

3 Idem, p. 198.

4 Idem, p. 265.

5 Maurice BLANCHOT. O Espaço Literário. Rio de Janeiro: Rocco, 1987, p. 21.

6 Érico VERÍSSIMO. Solo de Clarineta: memórias, 2 vols. $20^{a}$ ed. São Paulo: Companhia das Letras, 2005, p. 269.

7 Idem, p. 258.

8 Idem, p. 111.

9 Idem, p. 160.

10 Idem, p. 22.

11 Idem, p. 266.

12 Idem, p. 270.

13 Maurice BLANCHOT. O Espaço Literário. Rio de Janeiro: Rocco, 1987, p. 19-20.

14 Érico VERÍSSIMO. Solo de Clarineta: memórias, 2 vols. $20^{a}$ ed. São Paulo: Companhia das Letras, 2005, p. 269.

15 Maurice BLANCHOT. O Espaço Literário. Rio de Janeiro: Rocco, 1987, p. 16.

16 Idem

17 Maurice BLANCHOT. O Espaço Literário. Rio de Janeiro: Rocco, 1987, p. 71.

18 Maurice BLANCHOT. O Espaço Literário. Rio de Janeiro: Rocco, 1987, p. 19.

19 Franz KAFKA. Diário. Belo Horizonte: Itatiaia, 2000, p. 44.

20 Franz KAFKA. Diário. Belo Horizonte: Itatiaia, 2000, p. 17.

21 Franz KAFKA. Diário. Belo Horizonte: Itatiaia, 2000, p. 17.

22 Michel de CERTEAU. A operação historiográfica. In: A Escrita da História. Rio de Janeiro: Forense Universitária, 2002, p. 302.

23 Érico VERÍSSIMO. Solo de Clarineta: memórias, 2 vols. $20^{\mathrm{a}}$ ed. São Paulo: Companhia das Letras, 2005, p.11-12. 
24 Maurice BLANCHOT. O Espaço Literário. Rio de Janeiro: Rocco, 1987, p.18.

25 Maurice BLANCHOT. O Espaço Literário. Rio de Janeiro: Rocco, 1987, p. 79.

26 Maurice BLANCHOT. O Espaço Literário. Rio de Janeiro: Rocco, 1987, p. 69.

27 Maurice BLANCHOT. O Espaço Literário. Rio de Janeiro: Rocco, 1987, p. 63-65.

28 Referência a um dos livros de memórias escrito por Érico Veríssimo.

29 Érico VERÍSSIMO. Gato preto em campo de neve. São Paulo: Companhia das Letras, 2006.

30 Érico VERÍSSIMO. Gato preto em campo de neve. São Paulo: Companhia das Letras, 2006, p. 69-73.

31 Referencia ao enfarto sofrido por Érico Veríssimo em1961, que descreve como uma enorme sensação de sufocamento.

32 Érico VERÍSSIMO. Solo de Clarineta: memórias, 2 vols. $20^{\mathrm{a}}$ ed. São Paulo: Companhia das Letras, 2005, p. 29 e seguintes.

33 Érico VERÍSSIMO. Solo de Clarineta: memórias, 2 vols. $20^{\mathrm{a}}$ ed. São Paulo: Companhia das Letras, 2005, p. 67.

34 Maurice BLANCHOT. O Espaço Literário. Rio de Janeiro: Rocco, 1987, p. 67.

35 Maurice BLANCHOT. O Espaço Literário. Rio de Janeiro: Rocco, 1987, p.153.

36 Érico VERÍSSIMO. Solo de Clarineta: memórias, 2 vols. $20^{\mathrm{a}}$ ed. São Paulo: Companhia das Letras, 2005, p. 215.

37 Érico VERÍSSIMO. Solo de Clarineta: memórias, 2 vols. $20^{\mathrm{a}}$ ed. São Paulo: Companhia das Letras, 2005, p. 256.

38 Érico VERÍSSIMO. Solo de Clarineta: memórias, 2 vols. $20^{\mathrm{a}}$ ed. São Paulo: Companhia das Letras, 2005, p. 244.

39 Michel de CERTEAU. A operação historiográfica. In: A Escrita da História. Rio de Janeiro: Forense Universitária, 2002, p. 65-119.

40 Maurice BLANCHOT. O Espaço Literário. Rio de Janeiro: Rocco, 1987, p. 31.

41 Reinhart KOSELLECK. Futuro Passado: contribuição à semântica dos tempos históricos. Rio de Janeiro: Contraponto: Ed. PUC-Rio, 2006, p.305-327. 
42 Maurice BLANCHOT. O Espaço Literário. Rio de Janeiro: Rocco, 1987, p. 34.

43 Manoel de BARROS. Livro sobre nada. São Paulo: Record, 1996.

44 Érico VERÍSSIMO. Solo de Clarineta: memórias, 2 vols. $20^{\mathrm{a}}$ ed. São Paulo: Companhia das Letras, 2005, p. 270. 